\title{
Integration of Networks of Sensors and Electronics for Structural Health Monitoring of Composite Materials
}

\author{
Fabrizia Ghezzo, ${ }^{1}$ Anthony F. Starr, ${ }^{2}$ and David R. Smith ${ }^{1}$ \\ ${ }^{1}$ Department of Electrical and Computer Engineering, Duke University, P.O. Box 90291, Durham, NC 27708, USA \\ ${ }^{2}$ SensorMetrix, 10211 Pacific Mesa Blvd, Suite 408, San Diego, CA 92121, USA
}

Correspondence should be addressed to Fabrizia Ghezzo, fabrizia.ghezzo@duke.edu

Received 2 September 2009; Revised 24 February 2010; Accepted 29 March 2010

Academic Editor: Piervincenzo Rizzo

Copyright ( 92010 Fabrizia Ghezzo et al. This is an open access article distributed under the Creative Commons Attribution License, which permits unrestricted use, distribution, and reproduction in any medium, provided the original work is properly cited.

\begin{abstract}
The low-cost, widespread availability and robust nature of current electronic devices suggest the feasibility of creating a composite structure with integrated networked sensors to monitor in real time the life of civil and aerospace structures while in service conditions. For structures that need to survive to high number of life cycles under varying load-environmental conditions, it is of crucial importance that the strength, stiffness, endurance, and general load-bearing capabilities of the composite not to be severely degraded by the integrated networked components. Therefore, design tools must be developed to achieve optimized, safe, and reliable structures. High values of stress concentrations due to the presence of a rigid device within a highly anisotropic material can trigger the initiation of microcracks in the resin matrix. To quantify these effects, the acoustic emission technique is used to characterize the initiation of microfailures within laminated composites with integrated electronics.
\end{abstract}

\section{Introduction}

Health monitoring of composite structures and components for civil and aerospace applications has become of major interest in the past few decades. Advances in the microelectronics industry are clearly showing progressive success at achieving smaller chip and sensors sizes of consuming less power, while increasing the processing and functionality. However, such inclusions may affect the local integrity of fiber reinforced polymers and the limitation of the tolerability of the host material in presence of these devices must be quantified. With respect to structural performance, the effects of the embedded transducers on the host composite may be object of concern. The presence of inclusions causes material and geometrical discontinuities that are responsible of unwanted stress concentrations with consequences on the reduction of the stiffness and the overall material performance. For this reason, effort has been devoted into adding monitoring functionality into composites without compromising the structural integrity. To emphasize the importance of these studies a brief review of the literature which includes the first historical and significant contributions in this area is needed. These contributions are summarized in Table 1.

By reviewing these experimental studies, and as pointed out in a previous work [16], it appears that in cases where the thickness and the geometry of the implant did not alter significantly the through-the-thickness configuration of the host material, the impact on the surrounding material remains very small and has negligible effects on the material integrity. Where the integrated devices are not of negligible size, the strength reduction of the embedded material as well as the damage mechanisms need to be quantified and further investigated. These observations are of fundamental importance for material design considerations and final application of safe and reliable components.

This paper gives an overview of the failure mechanisms which develop in fiberglass epoxy laminates due to the presence of integrated electronic components which are "thick" if compared to the laminated material ply thickness and presents the importance of material design and selection of proper lay-up configurations. These types of autoclaved 
TABLE 1: List of some significant experimental contributions on the evaluation of the effects of integrated devices on the structural integrity of composite materials.

\begin{tabular}{|c|c|c|c|}
\hline Authors & Devices integrated & Material studied & Main findings and conclusions \\
\hline $\begin{array}{l}\text { Warkentin, and } \\
\text { Cawley } 1991[1]\end{array}$ & Circuits on silicon chips & $\begin{array}{l}\text { Graphite/epoxy } \\
\text { composites }\end{array}$ & $\begin{array}{l}\text { No change of in-plane mechanical properties. 15\% } \\
\text { reduction of the material strength. }\end{array}$ \\
\hline Kim et al. 1992 [2] & $\begin{array}{l}\text { Simulated thermocouples with } \\
0.381 \mathrm{~mm} \text { wire diameter. } \\
\text { Simulated strain gauge Kapton film } \\
\text { size: } 10.16 \mathrm{~mm} \times 5.08 \mathrm{~mm} 0.127 \mathrm{~mm}\end{array}$ & $\begin{array}{l}\text { Quasi isotropic } \\
\text { Fiberite T300/976 or } \\
\text { Fiberite APC-2 } \\
\text { graphite composites }\end{array}$ & $\begin{array}{l}\text { Negligible effects on the strength in uniaxial } \\
\text { compression and 3-point bending. }\end{array}$ \\
\hline $\begin{array}{l}\text { Holl, and Boyd } \\
1993[3]\end{array}$ & $\begin{array}{l}\text { Fiber Optic sensors (FO) with } \\
100-200 \mathrm{~mm} \text { diameter }\end{array}$ & $\begin{array}{l}\text { Unidirectional and } \\
\text { quasi isotropic } \\
\text { graphite laminates }\end{array}$ & $\begin{array}{l}\text { Failure does not initiate near the fiber-optic sensor. No } \\
\text { sensitivity to the embedded sensor is seen in } \\
\text { quasi-isotropic cases The transverse strength is reduced. }\end{array}$ \\
\hline $\begin{array}{l}\text { Sirkis, and Singh } \\
1994[4]\end{array}$ & Fiber Optic sensors (FO) & $\begin{array}{l}\text { Graphite composite } \\
\text { laminates }\end{array}$ & $\begin{array}{l}\text { Optical microscopy and Moiré interferometry show no } \\
\text { perturbation in the strain state of the material with } \\
\text { embedded FO. The material lay-up and its thickness } \\
\text { influence the results. }\end{array}$ \\
\hline $\begin{array}{l}\text { Singh, and Vizzini } \\
1994[5]\end{array}$ & Simulated actuator (glass slice) & $\begin{array}{l}\text { AS4/3501-6 } \\
\text { graphite/epoxy } \\
\text { laminates }\end{array}$ & $\begin{array}{l}\text { Interlacing results in } 42 \% \text { reduction of the max. } \\
\text { interlaminar tensile stress and a } 22 \% \text { reduction of the } \\
\text { max. interlaminar shear stress }\end{array}$ \\
\hline $\begin{array}{l}\text { Shukla, and Vizzini } \\
1996[6]\end{array}$ & $\begin{array}{l}\text { Simulated sensors/actuators. Device } \\
\text { size: } 25.4 \mathrm{~mm} \times 76.2 \mathrm{~mm} \times 1 \mathrm{~mm}\end{array}$ & $\begin{array}{l}\text { Unidirectional } \\
\text { AS4/3501-6 } \\
\text { graphite-epoxy } \\
\text { laminates }\end{array}$ & $\begin{array}{l}\text { The } 72 \% \text { material strength reduction u } \\
\text { loads improves with interlacing technic }\end{array}$ \\
\hline $\begin{array}{l}\text { Mall, and Coleman } \\
1998[7]\end{array}$ & $\begin{array}{l}\text { Active PZT sensors. Device size: } \\
50: 8 \mathrm{~mm} \times 25: 4 \mathrm{~mm} \times 0: 254 \mathrm{~mm}\end{array}$ & $\begin{array}{l}\text { Quasi-isotropic } \\
\text { AS4/3501-6 } \\
\text { graphite/epoxy } \\
\text { laminates }\end{array}$ & $\begin{array}{l}4 \% \text { reduction of strength and Young's modulus. No } \\
\text { degradation of the fatigue life. The embedded PZTs } \\
\text { maintain a steady output indefinitely if mechanically } \\
\text { cycled within their operational strain limits }\end{array}$ \\
\hline $\begin{array}{l}\text { Paget, and Levin } \\
1999[8]\end{array}$ & Active thin $(0.13 \mathrm{~mm})$ PZT sensors & $\begin{array}{l}\text { Quasi-isotropic } \\
\text { graphite/epoxy } \\
\text { laminates }\end{array}$ & No effects on the strength and the failure modes \\
\hline $\begin{array}{l}\text { Hansen, and } \\
\text { Vizzini } 2000[9]\end{array}$ & $\begin{array}{l}\text { Simulated devices (glass slices) size: } \\
76 \mathrm{~mm} \text { by } 25 \mathrm{~mm} \text { by } 1 \mathrm{~mm}\end{array}$ & $\begin{array}{l}\text { Unidirectional } \\
\text { AS4/3501-6 } \\
\text { graphite/epoxy } \\
\text { composites }\end{array}$ & $\begin{array}{l}\text { Static tension and tension-tension fatigue of interlaced } \\
\text { materials with devices: } 33 \% \text { reduction of strength; } \\
\text { endurance is improved; damage initiation delayed with } \\
\text { respect to the use of cut-out methods. }\end{array}$ \\
\hline $\begin{array}{l}\text { Mall, and Hsu } \\
2000[10]\end{array}$ & $\begin{array}{l}\text { Zirconate-titanate, PZT actuators } \\
\text { integrated with cut-out methods. } \\
\text { Device size: } 50.8 \mathrm{~mm} \times 25.4 \mathrm{~mm} \times \\
0.254 \mathrm{~mm}\end{array}$ & $\begin{array}{l}\text { AS4/3501-6 } \\
\text { graphite/epoxy } \\
\text { laminates }\end{array}$ & $\begin{array}{l}\text { Fatigue of active PZT. Specimens cycled at different } \\
\text { max stress levels while exciting the embedded actuator } \\
\text { from }-10 \mathrm{~V} \text { to }-100 \mathrm{~V} \text { or } 10 \mathrm{~V} \text { to } 100 \mathrm{~V} .10 \mathrm{~Hz} \text { and } R= \\
0.1 \text {. Embedded PZT performed better in the } \\
\text { out-of-phase than in-phase conditions. }\end{array}$ \\
\hline Mall 2002 [11] & $\begin{array}{l}\text { Active PZT sensors integrate with or } \\
\text { without cut-out method. Device size: } \\
50.8 \mathrm{~mm} \times 25.4 \mathrm{~mm} \times 0.254 \mathrm{~mm}\end{array}$ & $\begin{array}{l}\text { Quasi-isotropic } \\
\text { AS4/3501-6 } \\
\text { graphite/epoxy } \\
\text { laminates }\end{array}$ & $\begin{array}{l}\text { Tensile strength and Young's modulus are not affected } \\
\text { by the integration of actuator/sensor using the two } \\
\text { embedding techniques. No degradation in the fatigue } \\
\text { life/strength. The PZT actuator/sensor functions } \\
\text { mechanically fatigued or loaded to the maximum stress } \\
\text { level equal to its operational design limit. }\end{array}$ \\
\hline $\begin{array}{l}\text { Lin., and Chang } \\
2002[12]\end{array}$ & $\begin{array}{l}\text { Sensor network: thin flexible dielectric } \\
\text { film, SMART layer (printed circuit } \\
\text { material with piezoelectric on it). } \\
\text { Layer thickness: } 0.050 \text { to } 0.25 \mathrm{~mm}\end{array}$ & $\begin{array}{l}\text { Composites made } \\
\text { with RTM methods }\end{array}$ & $\begin{array}{l}\text { The SMART layer does not affect noticeably the } \\
\text { strength of the host composite structure, nor promote } \\
\text { delamination in } 3 \text { point bending tests. }\end{array}$ \\
\hline $\begin{array}{l}\text { Shivakumar, and } \\
\text { Emmanwori } 2004 \\
\text { and } 2005[13,14]\end{array}$ & $\begin{array}{l}\text { Samples with } 0,30,45,60,90^{\circ} \mathrm{FO} \\
\text { sensors oriented with respect the fibers } \\
\text { direction. }\end{array}$ & $\begin{array}{l}\text { Unidirectional } \\
\text { AS4/3501-6 } \\
\text { carbon/epoxy } \\
\text { laminates }\end{array}$ & $\begin{array}{l}\text { The material properties are unaffected by the } \\
\text { integration of the fiber-optic sensor. } 10 \% \text { reduction of } \\
\text { the tensile strength and } 40 \% \text { decrease of the } \\
\text { compressive strength are reported. }\end{array}$ \\
\hline $\begin{array}{l}\text { Ghasemi-Nejhad } \\
\text { et al. } 2005 \text { [15] }\end{array}$ & $\begin{array}{l}\text { Active flexible piezoceramic sensors } \\
\text { and actuators patches. Patches } \\
\text { dimensions: } 135 \mathrm{~mm} \times 55 \mathrm{~mm} \times \\
0.33 \mathrm{~mm} \text {. }\end{array}$ & $\begin{array}{l}\text { Plain weave } \\
\text { carbon/epoxy } \\
\text { material }\end{array}$ & $\begin{array}{l}\text { (1) Cutout holes, }(2) \text { molded-in holes, and ( } 3 \text { ) } \\
\text { embedding techniques. Manufacturing, durability, } \\
\text { dynamic, and structural performance of embedded } \\
\text { materials are optimal if materials with devices are made } \\
\text { with method (3) }\end{array}$ \\
\hline
\end{tabular}




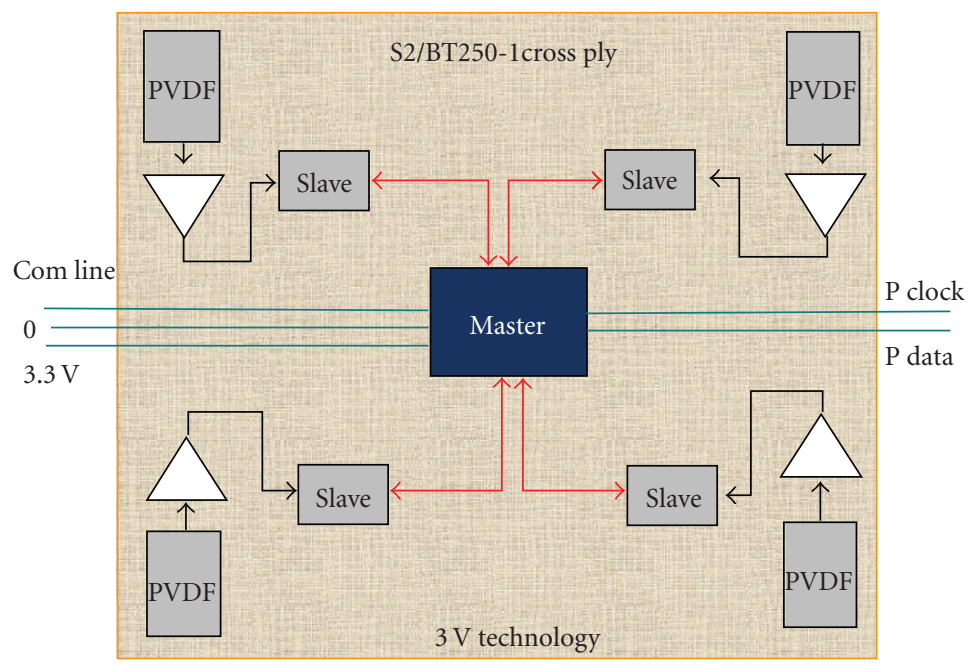

FIGURE 1: Schematic of one module of a 4-tree hierarchical network.

or compression molded materials are of common use in wind energy blades, aircrafts components, military devices, and military vehicles components for shock and blast energy absorption. The design of such structures requires careful experimental analyses on small samples and subsequent proof of research findings on actual components [17]. This last step is necessary since the fabrication and therefore the final quality of these materials combined with the environmental conditions at which the component is subjected during its life can affect the results obtained in the laboratory.

In this paper, laboratory results are mainly considered. Specifically, the quantification of the effects of integrated microelectronic components on the local integrity of the host material was investigated. In previous works [16, 18] the initiation of the damage within the material was assessed by continuously monitoring the samples subjected to tensile load with the acoustic emission technique. It was proved that the presence of notches in unidirectional plies induces microcracks into the resin that can propagate quickly along the fibers direction causing a fast degradation of the material in terms of mechanical properties and structural performance. The results previously obtained for unidirectional 0-degree fiber orientations (where the fiber orientation is considered with respect to the direction of the load applied) are compared with the results of experiments conducted on 45-degree laminates to show the importance of the material lay-up to optimize the resistance of these materials in presence of implanted devices.

\section{Materials and Properties}

The experimental investigations here presented were conducted in order to overcome some issues encountered for the fabrication, design, and development of an embeddable acoustic sensing network with optimized communication schemes. The targeted network was developed to be integrated into a thin laminated composite in order to enable the material to sense and locate matrix microcracks. A description of the overall system that was developed is given as an introduction to this section. The discussion will then continue focusing on the specific methodology adopted to overcome some of the issues that were encountered during the development of such system, particularly addressing the problem of stress concentrations due to the integration of external devices into polymeric matrix composites. It is important to point out that the results obtained from the impact that such devices have on the structural integrity of the material in fact-results mainly discussed in this paper-imposed the selection of the small and flexible electronic components that are illustrated and schematically represented in Figure 1. Today, electronic components are getting progressively smaller and more powerful with more memory presenting then the desirable features for our specific application. SiLab 8051 microprocessors $(3 \times 3 \times$ $1 \mathrm{~mm}$ ) were chosen as processing elements (PEs) of a 4tree hierarchical network [19]. This hierarchical network was selected since it may well represent, even though in its simplicity, neurological networks in living organisms. The integration and spatial allocation of components within the material was studied to maximize the reduction of wires and connections inside the material. The final modular structure created by combining the efforts in material lay-up optimization, proper selection of network and components, is presented in Figure 1.

It can be seen how each node is composed by a flexible and thin Polyvinilidene sensor (PVDF), a signal conditioning circuit (indicated in the figure with the triangle symbol), and a slave microprocessor. Each slave microchip has the function of analyzing the signal acquired by the sensor and amplified through the signal conditioning circuit and communicating the information of interest to the master. The desirable small size of the microprocessors is a limit to the available memory for processing data and basic functions. To overcome the problem due to their limited memory, the damage source identification and the classification of the damage events is 


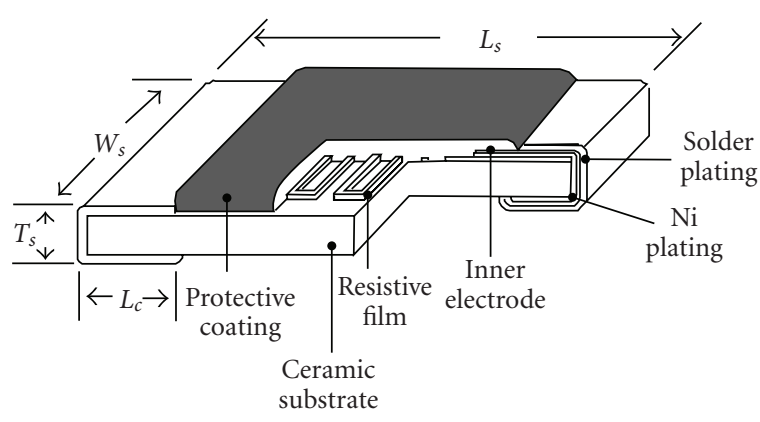

(a)

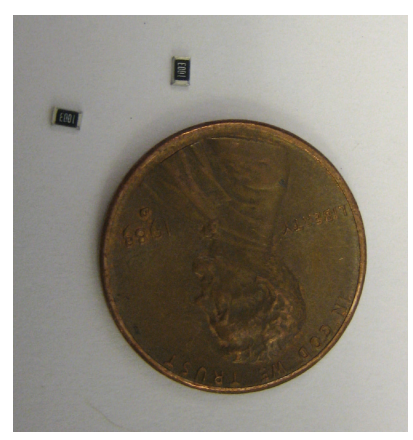

(b)

Figure 2: Schematic of the chip resistor 805, Koa Speer Electronics Inc.

TABLE 2: S2/BT250E-1LV material properties and lay-ups. *[20].

\begin{tabular}{|c|c|c|c|c|c|c|c|c|}
\hline \multicolumn{9}{|c|}{ Composite materials constituents properties } \\
\hline & & $\mathrm{E}(\mathrm{GPa})$ & $v_{12}$ & \multicolumn{2}{|c|}{$\mathrm{G}_{12}(\mathrm{GPa})$} & \multicolumn{2}{|c|}{$\sigma_{\mathrm{ftensile}}(\mathrm{MPa})$} & $\sigma_{\text {fshear }}(\mathrm{MPa})$ \\
\hline & & 86.9 & 0.23 & \multicolumn{2}{|c|}{35} & \multicolumn{2}{|c|}{4890} & $35^{*}$ \\
\hline BT250E & $\mathrm{V}$ resin & 3.86 & 0.39 & \multicolumn{2}{|c|}{1.39} & \multicolumn{2}{|c|}{75} & 35 \\
\hline \multicolumn{9}{|c|}{ Lamina properties } \\
\hline $\mathrm{E}_{11}(\mathrm{GPa})$ & $\mathrm{E}_{22}(\mathrm{GPa})$ & $\mathrm{E}_{33}(\mathrm{GPa})$ & $\mathrm{G}_{12}(\mathrm{GPa})$ & $\mathrm{G}_{13}(\mathrm{GPa})$ & $\mathrm{G}_{23}(\mathrm{GPa})$ & $v_{12}$ & $v_{13}$ & $\sigma_{f}(\mathrm{MPa})$ \\
\hline 47 & 7.6 & 7.6 & 2.77 & 2.77 & - & 0.29 & 0.29 & 1730 \\
\hline \multicolumn{3}{|c|}{ Blank samples } & \multicolumn{2}{|c|}{$[0]_{2}$} & {$\left[( \pm 45)_{5}\right]_{s}$} & & & \\
\hline \multicolumn{3}{|c|}{ Samples with embedded inclusions } & \multicolumn{2}{|c|}{$[0]_{6}$} & {$\left[( \pm 45)_{5}\right]_{s}$} & & & \\
\hline
\end{tabular}

conducted through the analysis of parametric information since they require a very limited use of the processor memory and processing functionalities. In summary, to successfully develop such system, the impact of external devices on the structural integrity of the material was deeply investigated. To do so we observed the effects that a general electronic component can have on the composite resin matrix while the material is subjected to external loads. Since the network was developed to acquire acoustic events in parametric form, the characterization of the material in the laboratory was conducted by monitoring its behavior under stress using the acoustic emission technique and analyzing the acquired parametric data. The main advantage of this method is the fact that the characterization of the acoustic emission behavior of the material in form of parametric information allows the direct implementation of the results into the microprocessors in form of lookup tables which are stored using a very limited amount of memory.

Given such conditions the successful development of this modular system was therefore possible only after the characterization of the acoustic events within the material and the calibration of the system in order to exclude that nonsignificant information (noise and general disturbance) is stored and processed as important event. From this introduction we can derive that the need of finding small electronic components to reduce the impact of such devices on the integrity of the material imposes also the need of searching for methods for efficient and fast data handling and storage. Besides the issues strictly related to the processing functions, the size limitations of these components required for this application are due to the built-in localized stress concentrations introduced by placing stiff implants into a material whose integrity relies mostly on the health status of its polymeric phase.

The material that has been used for this research is a multilayered composite made of S2 fiber glass BT250E-1LV epoxy resin prepreg by Bryte Composite Technologies Inc.

The samples were fabricated by using a vacuum bag technique with application of external pressure and were classified as follows: blank samples, without embedded implants, and samples with integrated microelectronic elements. To investigate the effects that general implants may have on this material, the microelectronics that were embedded during the hand layup fabrication consist of 0805 chip resistors, by Koa Speer Electronics Inc. These elements are active elements of the signal conditioning circuits for the network previously described. Their cost and availability made them perfectly suitable for these experiments.

These signal conditioning elements were placed at the mid-plane of the material stacking sequence. The 0805 chip resistor dimension is $2.03 \mathrm{~mm}\left(L_{S}\right)$ by $1.27 \mathrm{~mm}\left(W_{S}\right)$ by $0.55 \mathrm{~mm}\left(T_{S}\right)$. The device schematic is shown in Figure 2 with the sole purpose of better understanding the optical microscopy images presented in the following sections.

The samples present the device integrated and centrally located with respect to the two global in-plane axes. The main material and lamina properties are presented in Table 2. Following the standards [21], the fiber volume content, $V_{f}$, was found to be $53 \%$ for all the fabricated panels. The findings demonstrated that both types of samples, with and 
without embedded inclusions, display the same mechanical response (in plane properties and ultimate failure) in quasistatic tensile tests.

As it can be noticed in Table 2, the characterization of the $[0]_{n}$ laminates that was given in $[16,18]$ was carried out on six-layer samples in cases with embedded electronic components and two-layer samples in cases of material without inclusions. No changes in the failure mechanisms and acoustic behavior among samples of the same type with different number of plies were observed in these experiments. The failure always starts with matrix micro-crack phenomena induced by stress concentration at the device-composite matrix interface. The microcracks progressively grow and lead the sample to complete failure and loss of stiffness. While the characterization of the material response can be carried out on two ply laminates, four to six layers were necessary to properly integrate a $0.52 \mathrm{~mm}$ thick device. The external pressure applied to the vacuum bagged material can damage the fibers and indent them if there is not enough material to fully integrate the device.

The acoustic technique was used in this work to show that early low-medium amplitude events are detected at the rigid implant location in nonzero degree fiber orientations. Micrographic inspections conducted in parallel with the acoustic emission characterization of the material reveal that microcracks initiate at the device-composite matrix interface and grow around the implant causing the debond of the external component from the surrounding resin system. Material inhomogeneities are responsible for the formation of localized residual strains after the material fabrication. This fact is induced by the mismatch of the thermal properties between the resin and fibers $[22,23]$. Their negative effects can influence the matrix-fiber interface strength.

It is important to emphasize that the results in terms of amplitude and frequency and other parametric features of the acoustic emissions were not affected by the number of plies that constitute the samples analyzed; however the number of events occurring within the material, if the overall material behavior is considered, may change considerably. For this reason variables such as number of counts and accumulated number of counts were not taken into account for the analyses. The analysis of the characteristic features of the events related to the failure initiation and their classification is here presented. An overview of the overall failure mechanisms and amplitude events distribution is also reported. It can be anticipated that the integrated device did not seem to affect the in-plane material properties (independently from the material lay-up) and had a negligible effect on the material tensile strength in all cases analyzed. However, the failure process can be remarkably different.

\section{Experimental Procedure}

The samples were subjected to quasistatic tensile load up to failure and performed in ambient laboratory conditions and applying the load at a constant $0.02 \mathrm{~mm} / \mathrm{sec}$ displacement rate. The tests were monitored continuously by a PCI-2
TABLE 3: Acoustic emission system settings.

\begin{tabular}{lc}
\hline \multicolumn{2}{c}{ PCI-2 PAC system settings } \\
\hline Distance between the sensors & $50 \mathrm{~mm}$ \\
Number of sensors & $2-4$ \\
PDT (peak definition time) & $50 \mu \mathrm{sec}$ \\
HDT (hit definition time) & $300 \mu \mathrm{sec}$ \\
LDT (lock out definition time) & $800 \mu \mathrm{sec}$ \\
Threshold & $30-33 \mathrm{~dB}$ \\
Preamplification & $40 \mathrm{~dB}$ \\
Sampling rate & $2 \mathrm{MS} / \mathrm{s}$ \\
\hline
\end{tabular}

acoustic emission system by Physical Acoustic Corporation (PAC).

The acoustic emission technique is extensively used today as a nondestructive method for assessing microchanges and damage in materials and structures. It is generally used for maintenance of metallic as well as composite structures that must be periodically inspected after certain number of life cycles. Many efforts have been already made in the literature to categorize the different sources of damage within composites using this technique, such as matrix cracking, fiber-matrix debonding, fiber pull-out, fiber breakage, and interlaminar delamination through signal amplitude and other classical AE parameters or through frequency and wavelet analysis [24-27]. Since composites are well suited for amplitude distribution analysis, which has been recognized as a useful tool in diagnosing the material status and structural health, the following results are mainly presented as a comparison of the damage events amplitude identified in samples with and without integrated devices. Another reason for choosing to analyze only parametric information of acoustic emission events stands on the fact that the information achievable on the health of the component is possible through a limited number of transducers and limited memory usage. This fact helps in storing limited amount of data, saving processing time, selecting small processing elements and chip components, and consequently limiting the size of the circuits and wires to be integrated into the material.

The acoustic emission (AE) was detected through external R50D sensors with peak frequency at $175 \mathrm{kHz}$ and the data were collected and analyzed using AEWIN software [28]. Hsu-Nielsen tests were considered [29] to determine the speed of the acoustic waves within laminates with different fiber orientations necessary for the location of the acoustic sources. After completing these tests, the settings listed in Table 3 were selected for the use of the Physical Acoustic Corporation (PAC) system in these experiments.

The quasi-static tensile tests were performed using two acoustic transducers mounted on the surface of the sample using vacuum grease as couplant in order to improve the transmission of the signals through the sensor-sample interface. The AE parameters acquired during the experiments include events amplitude, events duration, number of counts per event, signal waveforms, and associated energy. Moreover, the information regarding the very first events 


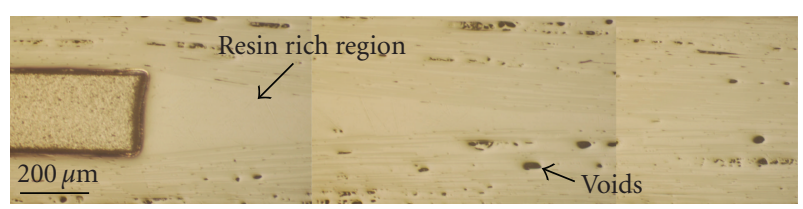

FIgURE 3: Photomicrograph of the resin pocket area around the embedded dummy sensor: side view (along the fiber direction).

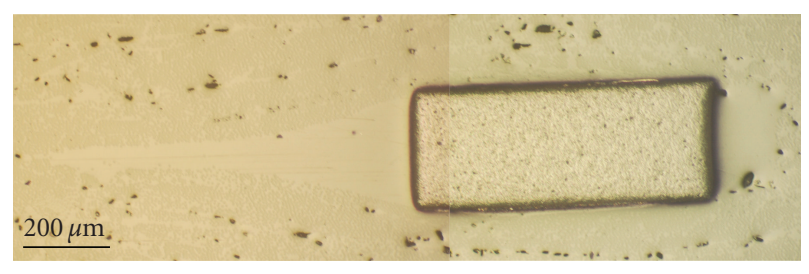

FIgURE 4: Photomicrograph of the resin pocket area around the embedded dummy microprocessor in \pm 45 degree laminates.

occurring in the load history was carefully examined. At least three samples were tested until failure and their behavior are compared. Parallel to the acoustic analyses, additional information on the material failure modes was extracted from the observation of the samples microstructure. Four pristine samples of each type (blank and with integrated electronics) were cut and polished and their microstructure was analyzed using standard optical microscopy. Some samples were cut in correspondence of the implant orthogonally to the fibers direction, others along the fibers. Figure 3 presents an amplified view of the sample cross section which shows the device implanted and the resin pocket region in a 0 -degree unidirectional fiber composite. As the micrographs show, the integration of relatively thick inclusions as actual commercially available microprocessors and signal conditioning elements forces the plies above and below the implant to deform, leaving large resin-rich regions. These effects were carefully analyzed in past both for fiberglass and for carbon fiber composites materials. The length of the resin-rich area was observed to be around $6 \mathrm{~mm}$. This was noticed to be true for 0 - and 90-degree fiber orientations (not shown here). Moreover, two resin-rich areas, symmetrically located with respect to the integrated electronic component, form along the fiber direction. It was demonstrated that orthogonally to the fibers the material around the dummy microprocessor appears uniformly to be distributed through the thickness.

If we compare the microstructure of these samples to nonzero fibers degree orientation samples, nonsymmetrical resin pockets with different shape and length can be observed instead; see Figure 4. Considerably reduced is also the length of this region in $[( \pm 45)]_{n}$ symmetrical laminates which was estimated to be at least tree times shorter than the one in unidirectional laminates. It must be also taken into account that, in general, the shape of this region depends also on the implanted device geometry.

Voids due to the curing of the resin and air eventually trapped within the material during the hand lay-up process were generally observed to be distributed between two adjacent plies as shown in the previous images. The total area of the sample cross section which is generally occupied by the voids was estimated in previous studies to be around $2 \%$ in samples both with and without embedded inclusions through image analysis. Moreover, it was also shown that the resin rich region as shown in Figures 3 and 4 was found to be intact. This was achieved by polishing progressively small coupons with different lay-ups to inspect their microstructure at different distances from the implant. For instance, the first image in Figure 5(a) shows the tip of the resin pocket area at almost $3 \mathrm{~mm}$ from the device, Figure 5(b) shows the cross section of the material at approximately $3 \mathrm{~mm}$ from the integrated device, while Figure 5(c) shows the surface of the device. In this way, the material microstructure after the fabrication as well as the resin pocket region integrity was explored. The observations were generally repeated on four different coupons.

The same procedure adopted to investigate the microstructure of pristine samples was used also to identify possible sites of micro-crack initiation into the resin matrix in samples that were subjected to predefined stress levels. For samples with integrated devices it was necessary to monitor the acoustic emission activity in order to detect at what stress levels the microdamage located and identified at the implant begins to occur. Given the difficulty associated with the micrographic investigation and the impossibility to predict the size of such cracks and their exact location around the device, the maximum stress level at which the samples were subjected was selected by looking for the acoustic emission results and plots of events location. Once considerable activity was seen at the device location, the test was stopped and the samples were gently removed from the grips by unloading them in a quasistatic mode. The experience gained by testing up to failure a first set of samples while monitoring their acoustic emission activity gave essential information on the stress/strain levels to be achieved in order to keep the cross-section of interest almost undamaged but for the microfailures present around the device. Therefore, after a certain applied stress was reached, the samples were unloaded and removed from the grips to be sectioned, polished, and analyzed. The results and details about these investigations are presented in the following sections.

\section{Experimental Results}

A recent classification of the acoustic events within glass fiber-reinforced composites is reported in [30]. Additionally, it has been demonstrated that in single-edge-notch laminated composites, the presence of stress concentrators induces a higher number of acoustic events with higher spectrum of frequencies than in unnotched materials [31]. Following these previous works similar results were demonstrated by Ghezzo et al. in [16].

The acoustic results are here presented in terms of the cumulative number of counts, also often referred as cumulative damage, acquired in unidirectional $[0]_{n}$, and 


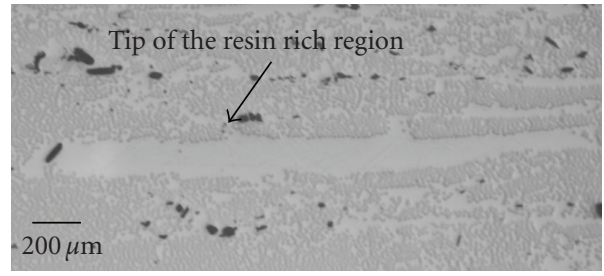

(a)

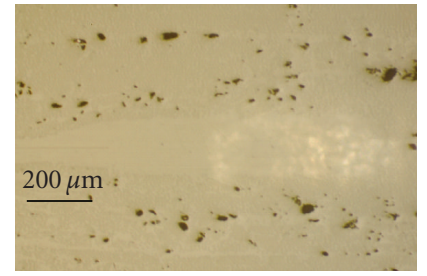

(b)

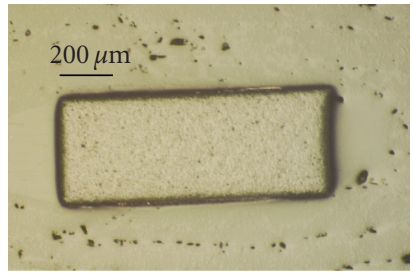

(c)

FIGURE 5: Tip of the resin pocket area in a 45-degree fiber orientation sample with integrated resistor at $3 \mathrm{~mm}$ from the implant, cross-section (a); at $0.5 \mathrm{~mm}$ from the implant, (b) and chip resistor cross-section (c) with magnification 50x.

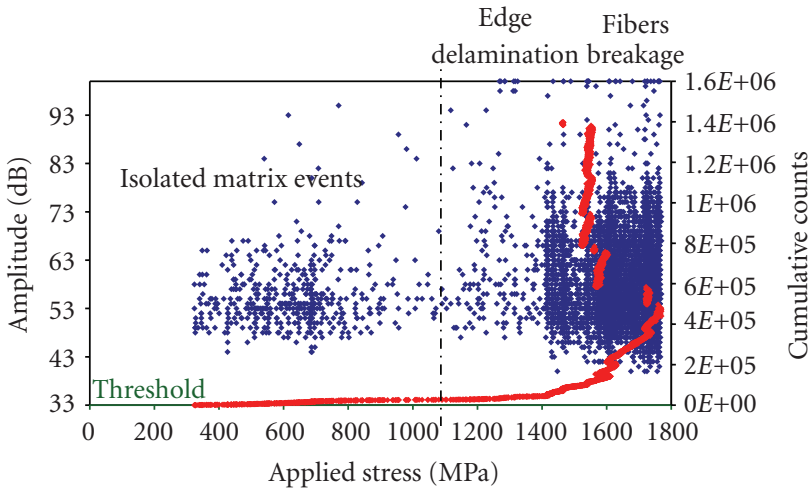

Figure 6: Typical acoustic behavior under tensile load of a sample without integrated inclusion.

$[ \pm 45]_{n}$ samples with and without integrated device during the loading history. Besides, the distribution of the events amplitude versus the increasing of the load applied is also shown.

Due to the uniqueness of each test, only some of the results obtained are here reported. However, at least four samples per type were tested and the results were found to be consistent. The results are summarized in Tables 3 and 4 at the end of this work.

4.1. Unidirectional $[0]_{n}$ Laminates. The results for this case were presented in a previous work [16]. In order to use these findings for comparing the results obtained from the characterization of samples with different fiber orientations we discuss the typical acoustic emission events recorded for these samples as given in Figures 6 and 7 giving some additional insights to this case that are useful for the comparison with nonzero-fiber laminates. The first acoustic emissions detected can be related to specific microfailures that occur inside the material. These two plots show the typical distribution of the events amplitude versus the applied stress in $[0]_{n}$ blank samples and samples with integrated devices. It can be observed that the acoustic emission events were detected at about $300 \mathrm{MPa}$ that we defined, as from a previous work, $\sigma_{\text {Fae-B }}$ which corresponds to the axial tensile stress at which first acoustic events begin in blank samples.

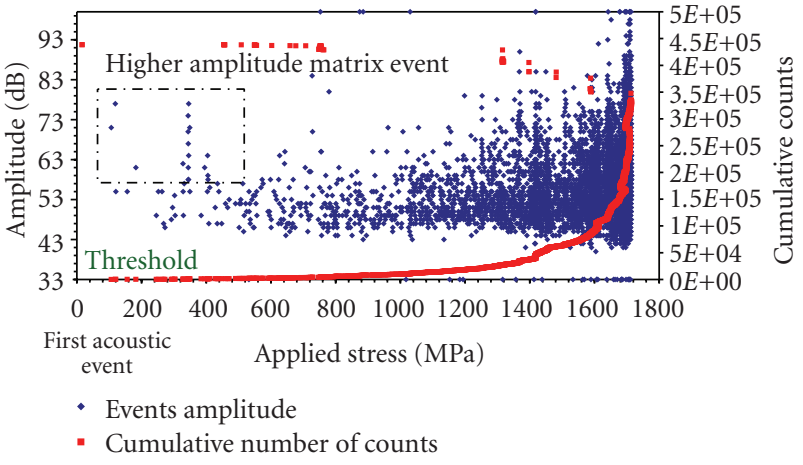

FIGURE 7: Typical acoustic behavior under tensile load of a sample with integrated inclusion.

The amplitude of these initial events was found in a range between 35-60 dB. In samples with embedded inclusions significant but isolated acoustic emissions were acquired at a stress which was named $\sigma_{\text {Fae-E}}$, the tensile stress at which first acoustic events are detected in samples with embedded inclusions. This stress was observed to be from $25 \%$ to $33 \%$ of $\sigma_{\text {Fae-B }}$, the stress at which first acoustic events are detected in samples without integrated devices for all the tests conducted. The amplitude of these early emissions generally falls into $50-75 \mathrm{~dB}$ range. Moreover, the distribution of the events was observed to be quite different in these two cases, and this fact can be attributed to a different failure process, clearly shown in Figures 8 and 9.

In samples with integrated device, the first acoustic emissions were detected and located in the material surrounding the implant. The distribution of the events in the case of samples with integrated device is concentrated at the center of the sample gage length where the device is located. This fact was found to be in agreement with the observed failure initiation and overall material failure. The location of the acoustic sources was determined based on the first threshold crossing time of the signals acquired by the external transducers and was identified at the implant, independently from the material lay-up. In order to correlate these acoustic occurrences with physical events, four $[0]_{6}$ samples with embedded electronic components were subjected to increasing tensile load until the first emissions were detected. Afterwards, the samples were removed from 


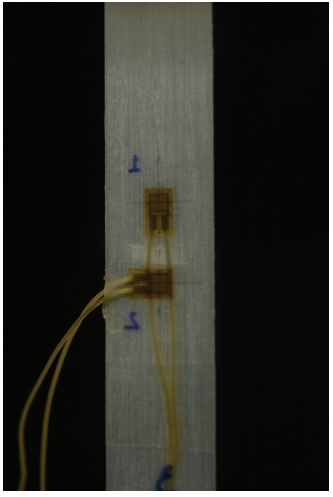

(a) $0 \mathrm{MPa}$

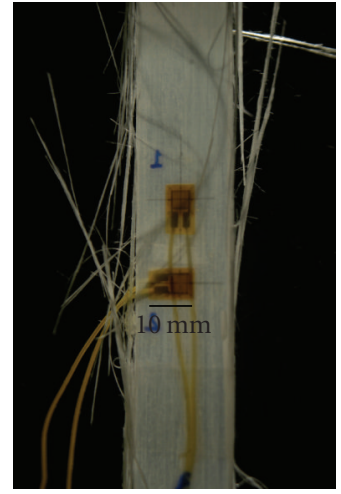

(b) $350 \mathrm{MPa}$

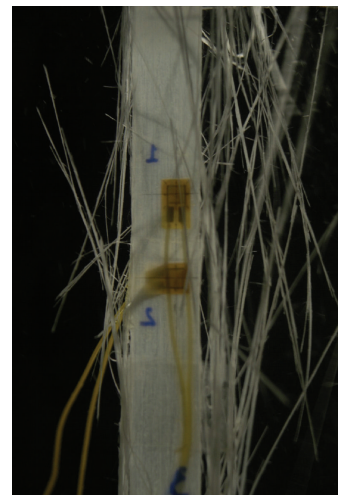

(c) $1000 \mathrm{MPa}$

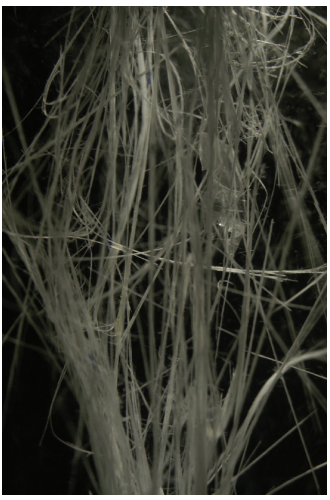

(d) $1700 \mathrm{MPa}$

FIGURE 8: Failure by progressive edge delamination in blank samples (a); initiation of the failure (b-c) and slow propagation; final failure (d).

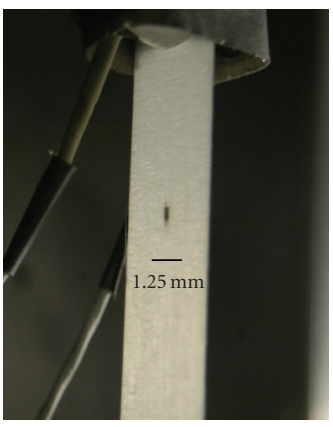

(a) $0 \mathrm{MPa}$

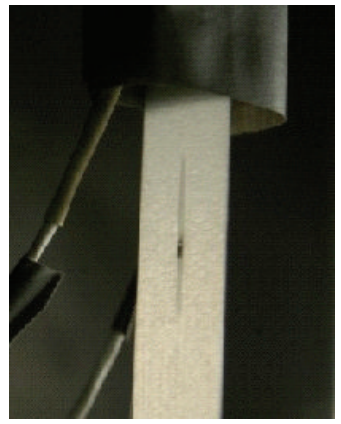

(b) $50-80 \mathrm{MPa}$

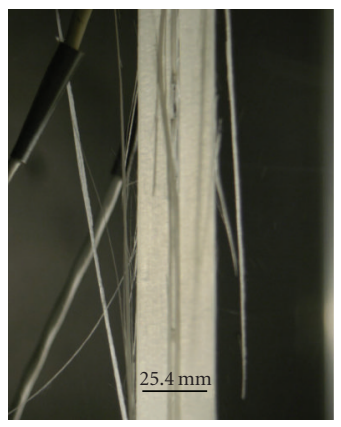

(c) $1000 \mathrm{MPa}$



(d) $1700 \mathrm{MPa}$

Figure 9: (a) through (c) initiation of failure at the implant in $[0]_{6}$ samples with integrated device; catastrophic failure (d).

the grips, cut orthogonally to the fibers at few millimeters from the implant, and polished. It was observed that even though acoustic events were captured at rather low stress levels, the samples chosen for microstructural investigations were subjected to higher loads in order to render the damage significant and visible; see Figure 10.

Guided by previous works in this field [30-32] and from the optical investigations conducted on tested samples, it appeared that the first acoustic events detected in blank glass fiber samples may be attributed to the growth of defects and flaws, fiber pull-out, and matrix microcracking phenomena. It was also observed that these first events are characterized by low amplitude $(35-60 \mathrm{~dB})$ and signal peak frequency between 100 and $180 \mathrm{kHz}$. Moreover, the distribution of the damage seemed to be uniform through the length of the sample.

On the other hand, in samples with integrated devices, localized cracks and debonding are mostly concentrated at the sensor-resin interface. The corresponding events acquired through the AE system are associated with low and medium amplitude signals $(50-70 \mathrm{~dB})$ with peak frequency in the range of $150-300 \mathrm{kHz}$. Even though the number of cumulative counts cannot be compared due to the different number of layers of these samples, the damage curves are qualitatively similar. The much lower cumulative number of counts acquired in samples with integrated device is however an additional indicator of the fast, catastrophic failure for growth of microcracks that start at the implant-composite interface and then propagate without obstacles within the resin matrix, along the fibers.

4.2. Symmetric $\left[( \pm 45)_{n}\right]_{s}$ Laminates. Unlike $[0]_{n},\left[( \pm 45)_{n}\right]_{s}$ laminates with integrated thick electronic devices presented a different failure mechanism. As shown in Figure 11, the final failure did not occur at the implant location. This fact was observed in all samples tested. Besides, the material response and the overall acoustic events amplitude distribution were found to be the same for both types of samples; see Figures 12 and 13. Even though early microcracks were detected at the implant location, other distributed sources of damage initiation were acquired within the material and the final failure occurred far from the embedded device. The propagation of early microcracks at the sensor-matrix interface therefore seemed to be restrained by the glass fibers. Localized high damage such as resin-sensor interface debonding, cracks opening, and fiber matrix debonding near the dummy microprocessor was identified through a series of micrographic inspections once the early acoustic events were detected. 


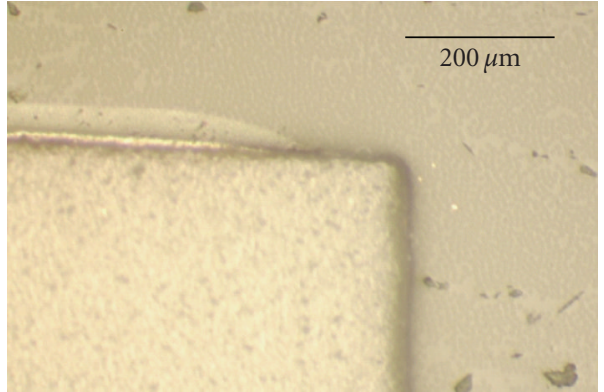

(a)

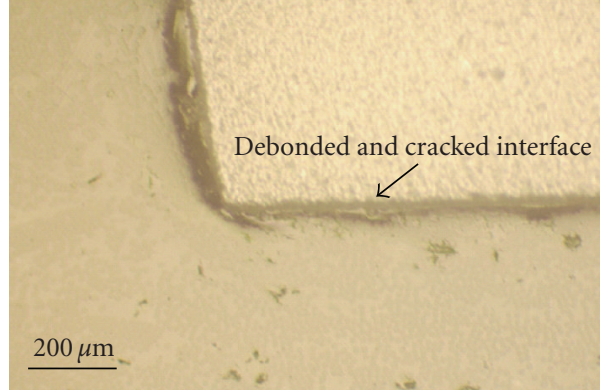

(b)

Figure 10: Photomicrographs of the cross-section around the dummy sensor of one virgin sample (a) and of one sample tested until $400 \mathrm{MPa}$ (b).

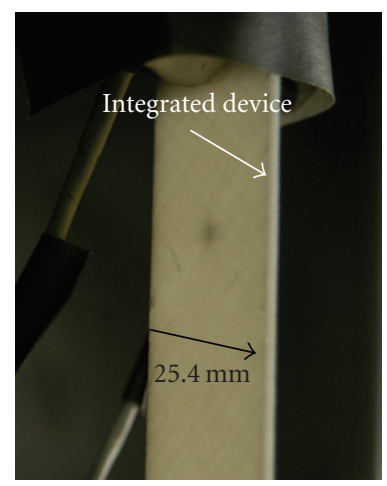

(a)

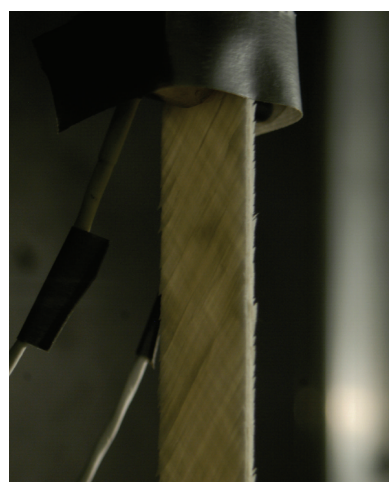

(b)

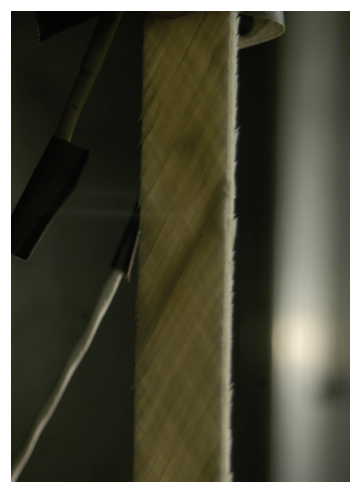

(c)

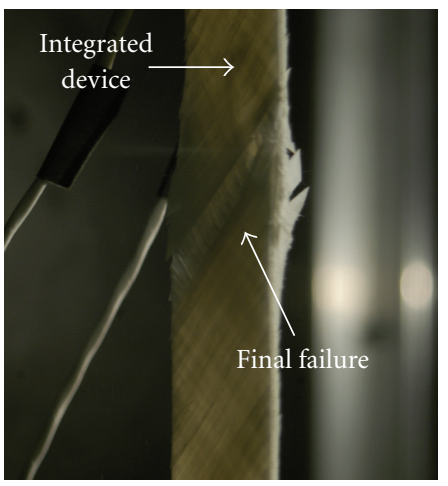

(d)

FiguRE 11: Typical failure mode of $\left[( \pm 45)_{5}\right]_{\mathrm{S}}$ samples with integrated dummy microprocessor, sample width $25.4 \mathrm{~mm}$.

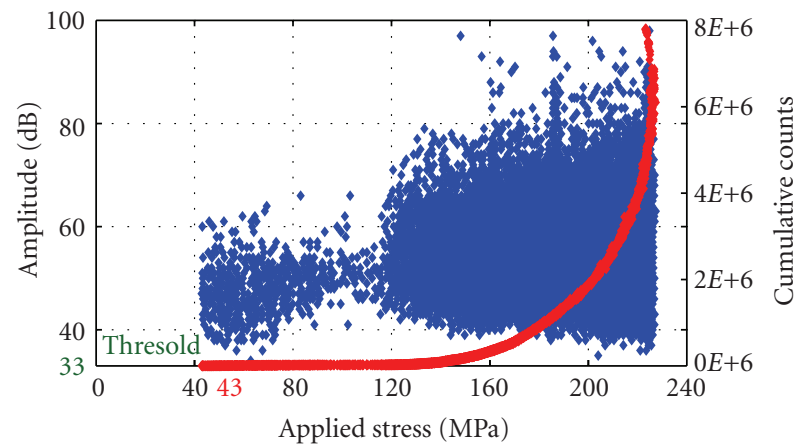

Figure 12: Cumulative damage and amplitude distribution of acoustic events in samples without integrated device.

As observed in $[0]_{n}$ samples, also in $\left[( \pm 45)_{5}\right]_{s}$ laminates acoustic emission events initiated in samples with integrated inclusion at almost $1 / 4$ of the external stress applied on blank samples which is seen to cause early emissions. The distribution of these events amplitude is characterized by values ranging between $43-65 \mathrm{~dB}$ while those observed in blank samples are mainly detected within 40 and $50 \mathrm{~dB}$. Once again, the frequency of these first events is higher than the one of events detected in blank samples. Generally the frequency of these first events was found to be around

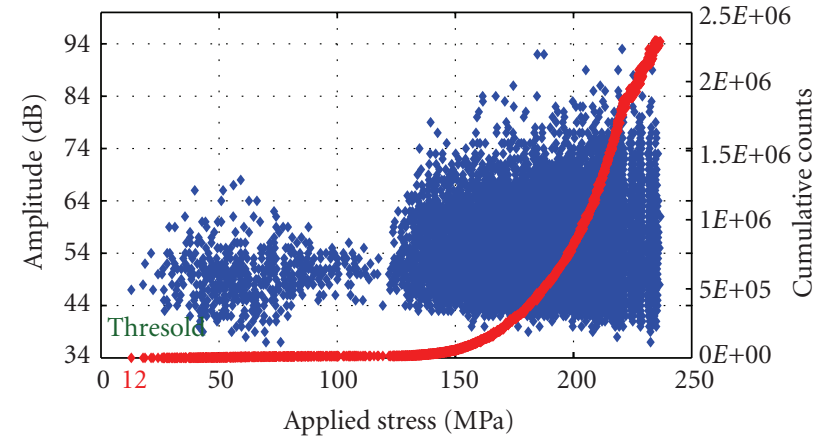

Figure 13: Cumulative damage and amplitude distribution of acoustic events in samples with integrated device.

$180 \mathrm{kHz}$. Isolated higher-frequency events, up to $350 \mathrm{kHz}$, were also acquired. In blank samples the frequency range varies between 130 and $170 \mathrm{kHz}$. As for the previous $[0]_{n}$ cases, we subjected some samples to a tensile load until the first acoustic events were detected. Afterwards, the samples were removed from the grips and polished in order to inspect their microstructure. The results are presented in Figure 14. Big flaws and voids were observed while the resin rich region was found to be intact. Microcracks were instead observed all around the inclusion. 


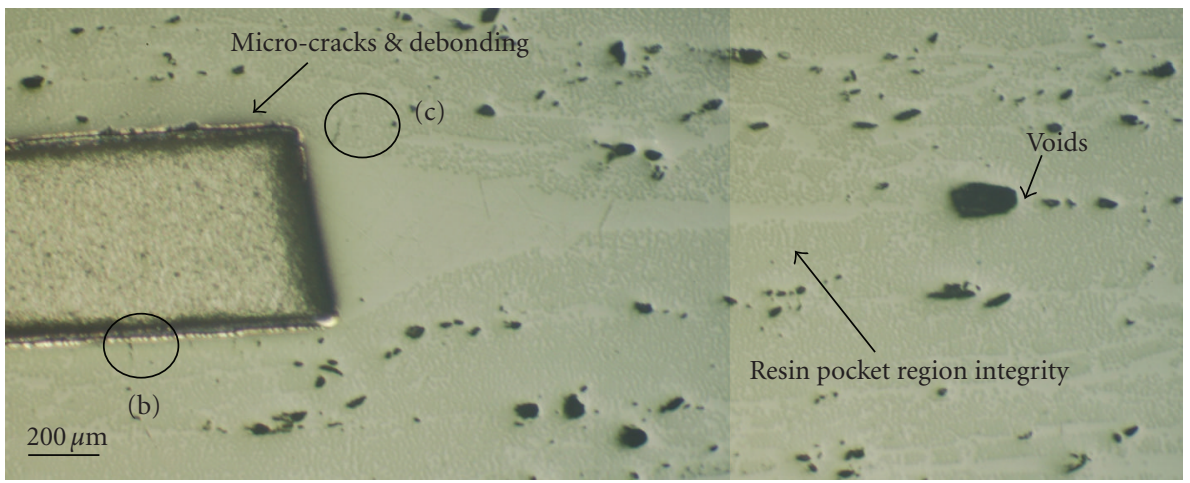

(a)

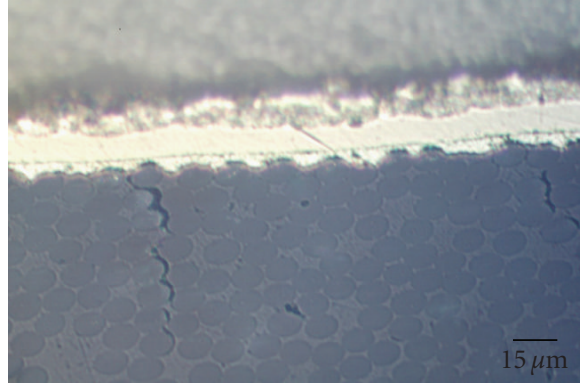

(b)

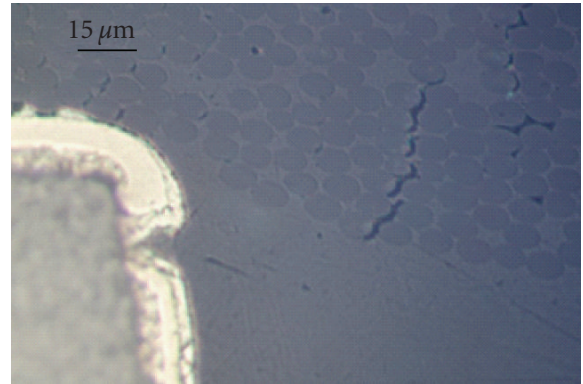

(c)

FIGURE 14: Sample cross-section and amplified views of debonding and microcracks around the integrated device after $100 \mathrm{MPa}$ were applied on the sample.

In conclusion, the acoustic emission results obtained on $[0]_{n}$ and $\left[( \pm 45)_{5}\right]_{s}$ laminates are summarized in Tables 4 and 5. Further experimental analyses on the initiation of failure within anisotropic media with integrated rigid thick inclusions seem to be still necessary and would greatly improve the understanding of the effects of integrated electronics on the local integrity of layered composites providing essential information for the development of new, thin, and eventually flexible sensors, more compatible with the host composite and therefore with minimal effects on the material.

\section{Concluding Remarks}

The integrity and mechanical response of fiberglass composites with integrated structural health monitoring sensors and electronic components is presented in this work. Particularly, the damage initiation and identification have been observed by conducting monotonic tensile tests on samples while continuously monitoring their acoustic emissions. A series of micrographic inspections was also conducted. Our major experimental observations can be summarized as follows.

(i) The mechanical response under quasistatic characterization of $[0]_{n}$ and $\left[( \pm 45)_{5}\right]_{s}$ laminates with integrated devices is substantially the same of that characterizing the material without integrated small signal conditioning components. The tensile strength of $[0]_{n}$ and $\left[( \pm 45)_{5}\right]_{s}$ presents a negligible reduction with respect to that of the blank samples.

(ii) The embedment process causes material and geometrical discontinuities within the composite laminate which creates large interlaminar eye-shaped resin pockets around the implant. Nonuniform fiber spacing is observed around these regions. The length of these resin-rich regions depends on the material layup. It is considerably smaller in nonzero degree fiber orientations.

(iii) Sharp geometrical discontinuities and material inhomogeneities are responsible for localized values of the stress concentrations which affect the initiation of the failure and its development around the inclusion.

(iv) Early acoustic events are detected at the sensor location at almost one quarter of the stress that is observed to induce acoustic activity in the material without implants. Moreover, the amplitude of the events acquired is usually higher than those noticed in samples without implants.

(v) The frequency of the early events in $[0]_{n}$ blank samples is within a $100-180 \mathrm{kHz}$ range and is mainly attributed to the growth of flaws and fiber pullout, while those detected in samples with integrated 
TABLE 4: Material without and with embedded inclusions: tensile strength and acoustic behavior.

\begin{tabular}{|c|c|c|c|c|c|c|c|}
\hline$[0]_{n}$ & Number of samples & $\sigma_{\mathrm{FAE}}$ Average $(\mathrm{MPa})$ & $\mathrm{DS}^{* *}$ & $\mathrm{CV} \%{ }^{* *}$ & Strength Average (MPa) & DS & $\mathrm{CV} \%$ \\
\hline Blank samples & 5 & 319.6 & 20.07 & 6.15 & 1729.4 & 40 & 2.33 \\
\hline Samples with integrated device & 5 & 89.7 & 22.18 & 24.7 & 1685 & 39.9 & 2.37 \\
\hline \multirow{2}{*}[(\pm45)_{5}]{$_{\mathrm{s}}$} & Results & $* \sigma_{\mathrm{tE}} / \sigma_{\mathrm{tB}}$ & \multicolumn{2}{|c|}{$97.42 \%$} & $\sigma_{\text {FAE-B }} / \sigma_{\text {FAE-E }}$ & \multicolumn{2}{|c|}{3.56} \\
\hline & Number of samples & $\sigma_{\mathrm{FAE}}$ Average $(\mathrm{MPa})$ & DS** & $\mathrm{CV} \%{ }^{* *}$ & Strength Average (MPa) & DS & $\mathrm{CV} \%$ \\
\hline Blank samples & 3 & 34.46 & 8.05 & 23.37 & 220 & 5.19 & 2.36 \\
\hline \multirow[t]{2}{*}{ Samples with integrated device } & 3 & 12.53 & 1.61 & 12.89 & 229 & 5.03 & 2.19 \\
\hline & Results & $* \sigma_{\mathrm{t}} \mathrm{E} / \sigma_{\mathrm{tB}}$ & \multicolumn{2}{|c|}{$36.37 \%$} & $\sigma_{\mathrm{FAE}-\mathrm{B}} / \sigma_{\mathrm{FAE}-\mathrm{E}}$ & \multicolumn{2}{|c|}{2.9} \\
\hline
\end{tabular}

* $\sigma_{\mathrm{tE}}$ : tensile strength of the material with integrated inclusion; $\sigma_{\mathrm{tB}}$ : tensile strength of blank samples; $\sigma_{\mathrm{FAE}-\mathrm{B}}$ : stress at which the acoustic events start in blank samples; $\sigma_{\mathrm{FAE}-\mathrm{E}}$ : stress at which the events begin in sample with embedded device.

**DS: Standard Deviation; CV: coefficient of variation; definitions according to ASTM 3039M.

TABLE 5: Material with and without integrated inclusions: stress, amplitude, and frequency range of the first acoustic events, and their classification. The lower and upper limits of each range are the lower and upper values observed among all the experiments conducted. Only the events in a stress window of about $20 \mathrm{MPa}$ have been considered. Results from $[0]_{n}$ laminates [16] are here reported for comparison.

\begin{tabular}{|c|c|c|c|c|}
\hline Lay-up & $\begin{array}{l}\text { Stress range of first } \\
\text { AE events }(\mathrm{MPa})\end{array}$ & $\begin{array}{c}\text { First AE Events } \\
\text { Amplitude range }(\mathrm{dB})\end{array}$ & $\begin{array}{l}\text { Peak Frequency of } \\
\text { first AE events }(\mathrm{kHz})\end{array}$ & $\begin{array}{l}\text { Event type classification based on } \\
\text { micrographic inspections }\end{array}$ \\
\hline Blank Samples $[0]_{2}$ & $320-400$ & $35-60$ & $100-180$ & $\begin{array}{l}\text { Matrix microcracking, fiber } \\
\text { pull-out }\end{array}$ \\
\hline Sample with device $[0]_{6}$ & 89-106 & $50-75$ & $150-300$ & $\begin{array}{l}\text { Matrix micro-cracking at the } \\
\text { sensor interface, debonding } \\
\text { events }\end{array}$ \\
\hline Blank Samples $\left[( \pm 45)_{5}\right]_{s}$ & $33-43$ & $40-50$ & $130-170$ & $\begin{array}{l}\text { Matrix micro-cracking, } \\
\text { debonding, }\end{array}$ \\
\hline Sample with device $\left[( \pm 45)_{5}\right]_{\mathrm{s}}$ & $10-14$ & $43-65$ & $150-350$ & $\begin{array}{l}\text { Matrix micro-cracking at the } \\
\text { sensor interface, debonding } \\
\text { events, friction }\end{array}$ \\
\hline
\end{tabular}

dummy microprocessors fall within a higher range of $150-300 \mathrm{kHz}$ and are classified as matrix cracking and debonding phenomena. A series of micrographic inspections was conducted to support these observations.

(vi) The frequency of the early events in $\left[( \pm 45)_{5}\right]_{\mathrm{s}}$ samples without inclusions is within a $145-280 \mathrm{kHz}$ range and is again attributed to the growth of flaws and fiber pull-out, and debonding, while that detected in samples with dummy microprocessors falls within a higher range of $150-350 \mathrm{kHz}$ and is classified as matrix cracking and debonding phenomena at the inclusion-matrix interface with friction and debonding phenomena. A series of micrographic inspections was conducted to support these observations.

The experiments show that the failure initiates at the implant-composite resin interface by interface debonding and microcracks around the device due to the high values of interlaminar stress. Large flaws at the implant-composite resin interface that were not generally observed in samples inspected prior to testing indicate that high stresses were likely responsible for the interface failure. Moreover, no sign of damage at the same stress level was observed at the tip of the resin pocket.

\section{Discussion}

This paper describes the impact of integrated implants on the local integrity of nonzero fiber-laminated composites compared to zero fiber-oriented laminates of standard laboratory size samples. These results add fundamental details on the initiation of the failure at the interface implant-composite resin matrix. The aim of this work has been in fact the identification of the effects of the integration of electronics together with sensors into laminated composites in order to encourage a careful analysis and design optimization while developing smart materials. The embedded implants consist either in signal conditioning devices (chip resistors) or in microprocessors (not shown in this work) which are generally part of circuits to be integrated into the material. Notwithstanding the remarkable improvements achieved in the sensors technology so that miniaturized, thin, highly deformable, resin compatible, and high temperature resistance transducers may be commercially available, electronic devices (microprocessors) still represent rigid thick inclusions to the host material. Therefore, attempting to embed them in order to create material with a fully integrated sensing network still requires some attention. Even though still at laboratory level, this research seems to be not far to its implementation into civil and aerospace materials. Besides, 
the analysis and quantification of the stress concentration and the interaction implant-composite can contribute enormously to the development of new electronic devices and sensors stimulating new fabrication techniques and procedures to minimize the impact of the implant on the specific material chosen. To date, there are no in-service components with fully integrated sensing systems hierarchically organized which monitor in real time the damage growth into the material. This fact is partially due to the many aspects and variables involved in the process that leads to the optimization of materials and components performance if in presence of integrated networks. Moreover, in general, the implementation of acoustic sensors seems to be a useful and well-established tool for successful passive and active damage detection with minimum number of sensors, reasonable memory usage, and therefore limited processors functions. In particular, we described the system that was developed taking into account such observations and that consists on a 4-tree hierarchical network of flexible PVDF sensors used for passive acoustic emission detection and connected to small microprocessors with limited memory. The processing functions that consist in location and classification of the damage events were possible using parametric features of the acquired acoustic signals. Minimization of issues due to stress concentration that can be induced by the presence of wires necessary to establish the connections among all sensors and electronics that constitute the network may be avoided by the implementation of systems based on wireless communication. Many of these aspects are currently under investigation.

We can conclude by emphasizing that the development of smart, multifunctional composite materials is possible but can be successful only if a proper sensors design, integration techniques, signal processing, data collection, and investigation of the limits of the material performance for actual components are considered.

\section{Acknowledgments}

The authors acknowledge the Center of Excellence for Advanced Materials, Department of Mechanical and Aerospace Engineering at the University of California San Diego, where the tensile tests on the S2/glass fiber samples were conducted, and the National Science Foundation, which supported this work under the Grant no. 0330450.

\section{References}

[1] J. Warkentin and E. F. Cawley, "Embedded electronics for intelligent structures," in Proceedings of the AIAA/ASME/ ASCE/AHS/ASC 32nd Structures, Structural Dynamics and Materials Conference, pp. 1322-1331, Baltimore, Md, USA, 1991.

[2] K. S. Kim, M. Breslauer, and G. S. Springer, "Effect of embedded sensors on the strength of composite laminates," Journal of Reinforced Plastics and Composites, vol. 11, no. 8, pp. 949-958, 1992.

[3] M. W. Holl and S. Boyd, "Effect of embedded fiber optics on the mechanical properties of a composite host material," in Smart Structures and Materials 1993: Smart Materials, vol. 1916 of Proceedings of SPIE, pp. 109-117, 1993.

[4] J. S. Sirkis and H. Singh, "Moiré analysis of thick composites with embedded optical fibers," Experimental Mechanics, vol. 34, no. 4, pp. 300-305, 1994.

[5] D. A. Singh and A. J. Vizzini, "Structural integrity of composite laminates with interlaced actuators," Smart Materials and Structures, vol. 3, no. 1, pp. 71-79, 1994.

[6] D. R. Shukla and A. J. Vizzini, "Interlacing for improved performance of laminates with embedded devices," Smart Materials and Structures, vol. 5, no. 2, pp. 225-229, 1996.

[7] S. Mall and J. M. Coleman, "Monotonic and fatigue loading behavior of quasi-isotropic graphite/epoxy laminate embedded with piezoelectric sensor," Smart Materials and Structures, vol. 7, no. 6, pp. 822-832, 1998.

[8] C. A. Paget and K. Levin, "Structural integrity of composites with embedded piezoelectric ceramic transducer," in Proceedings of the Smart Structures and Materials-Smart Structures and Integrated Systems, Proceedings of SPIE, pp. 306-313, 1999.

[9] J. P. Hansen and A. J. Vizzini, "Fatigue response of a host structure with interlaced embedded devices," Journal of Intelligent Material Systems and Structures, vol. 11, no. 11, pp. 902-909, 2000.

[10] S. Mall and T. L. Hsu, "Electromechanial fatigue behavior of graphite/epoxy laminate embedded with piezoelectric actuator," Smart Materials and Structures, vol. 9, no. 1, pp. 78-84, 2000.

[11] S. Mall, "Integrity of graphite/epoxy laminate embedded with piezoelectric sensor/actuator under monotonic and fatigue loads," Smart Materials and Structures, vol. 11, no. 4, pp. 527533, 2002.

[12] M. Lin and F. K. Chang, "The manufacture of composite structures with a built-in network of piezoceramics," Composites Science and Technology, vol. 62, no. 7-8, pp. 919-939, 2002.

[13] K. Shivakumar and L. Emmanwori, "Mechanics of failure of composite laminates with an embedded fiber optic sensor," Journal of Composite Materials, vol. 38, no. 8, pp. 669-680, 2004.

[14] K. Shivakumar and L. Emmanwori, "Failure mechanics of a composite laminate embedded with a fiber optic sensor," Journal of Composite Materials, vol. 39, no. 9, pp. 777-798, 2005.

[15] M. N. Ghasemi-Nejhad, R. Russ, and S. Pourjalali, "Manufacturing and testing of active composite panels with embedded piezoelectric sensors and actuators," Journal of Intelligent Material Systems and Structures, vol. 16, no. 4, pp. 319-333, 2005.

[16] F. Ghezzo, Y. Huang, and S. Nemat-Nasser, "Onset of resin micro-cracks in unidirectional glass fiber laminates with integrated SHM sensors: experimental results," Structural Health Monitoring, vol. 8, no. 6, pp. 477-491, 2009.

[17] A. Dasgupta, Y. Wan, and J. S. Sirkis, "Prediction of resin pocket geometry for stress analysis of optical fibers embedded in laminated composites," Smart Materials and Structures, vol. 1, no. 2, pp. 101-107, 1992.

[18] Y. Huang, F. Ghezzo, and S. Nemat-Nasser, "Onset of resin micro-cracks in unidirectional glass fiber laminates with integrated SHM sensors: numerical analysis," Structural Health Monitoring, vol. 8, no. 6, pp. 493-507, 2009.

[19] F. Ghezzo, P. Rye, Y. Huang, and S. Nemat-Nasser, "Integration of sensing networks into laminated composites," in Behavior and Mechanics of Multifunctional and Composite Materials, vol. 6929 of Proceedings of SPIE, pp. V.1-V.4, 2008. 
[20] I. M. Daniel and O. Ishai, Engineering Mechanics of Composite Materials, Oxford University Press, Oxford, UK, 2006.

[21] ASTM E976-00, "Standard guide for determining the reproducibility of acoustic emission sensor response".

[22] S. C. Tan, Stress Concentration in Laminated Composites, Technomic, 1994.

[23] S. G. Lekhnitskii, Anisotropic Plates, Gordon and Breach, New York, NY, USA, 1968.

[24] J. C. Radon and A. A. Pollock, "Acoustic emissions and energy transfer during crack propagation," Engineering Fracture Mechanics, vol. 4, no. 2, pp. 295-310, 1972.

[25] A. A. Pollock, "Acoustic emission-2 acoustic emission amplitudes," Non-Destructive Testing, vol. 6, no. 5, pp. 264-269, 1973.

[26] M. A. Gorman and W. H. Prosser, "AE source orientation by plate wave analysis," Journal of Acoustic Emission, vol. 9, no. 4, pp. 283-288, 1991.

[27] W. H. Prosser, M. A. Gorman, and D. H. Humes, "Acoustic emission signal in thin plates produced by impact damage," Journal of Acoustic Emission, vol. 17, no. 1-2, pp. 29-36, 1999.

[28] PCI-2 Based AE System User's Manual Physical Acoustic Corporation.

[29] ASTM D 2584-02, "Standard test methods for ignition loss of cured reinforced resins".

[30] X. Zhuang and X. Yan, "Investigation of damage mechanisms in self-reinforced polyethylene composites by acoustic emission," Composites Science and Technology, vol. 66, no. 3-4, pp. 444-449, 2006.

[31] S. C. Woo and N. S. Choi, "Analysis of fracture process in single-edge-notched laminated composites based on the high amplitude acoustic emission events," Composites Science and Technology, vol. 67, no. 7-8, pp. 1451-1458, 2007.

[32] P. J. De Groot, P. A. M. Wijnen, and R. B. F. Janssen, "Real-time frequency determination of acoustic emission for different fracture mechanisms in carbon/epoxy composites," Composites Science and Technology, vol. 55, no. 4, pp. 405-412, 1995. 

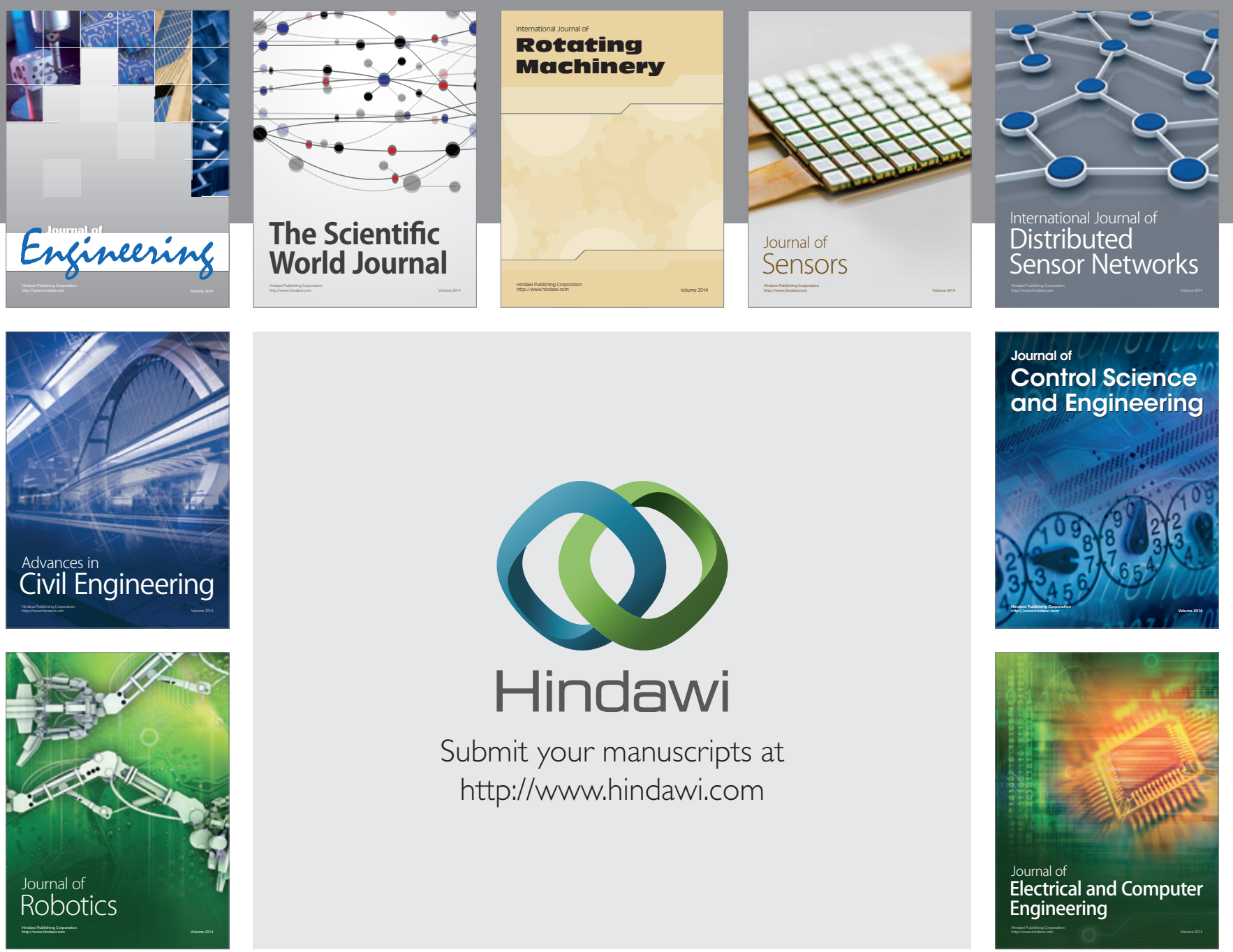

Submit your manuscripts at

http://www.hindawi.com
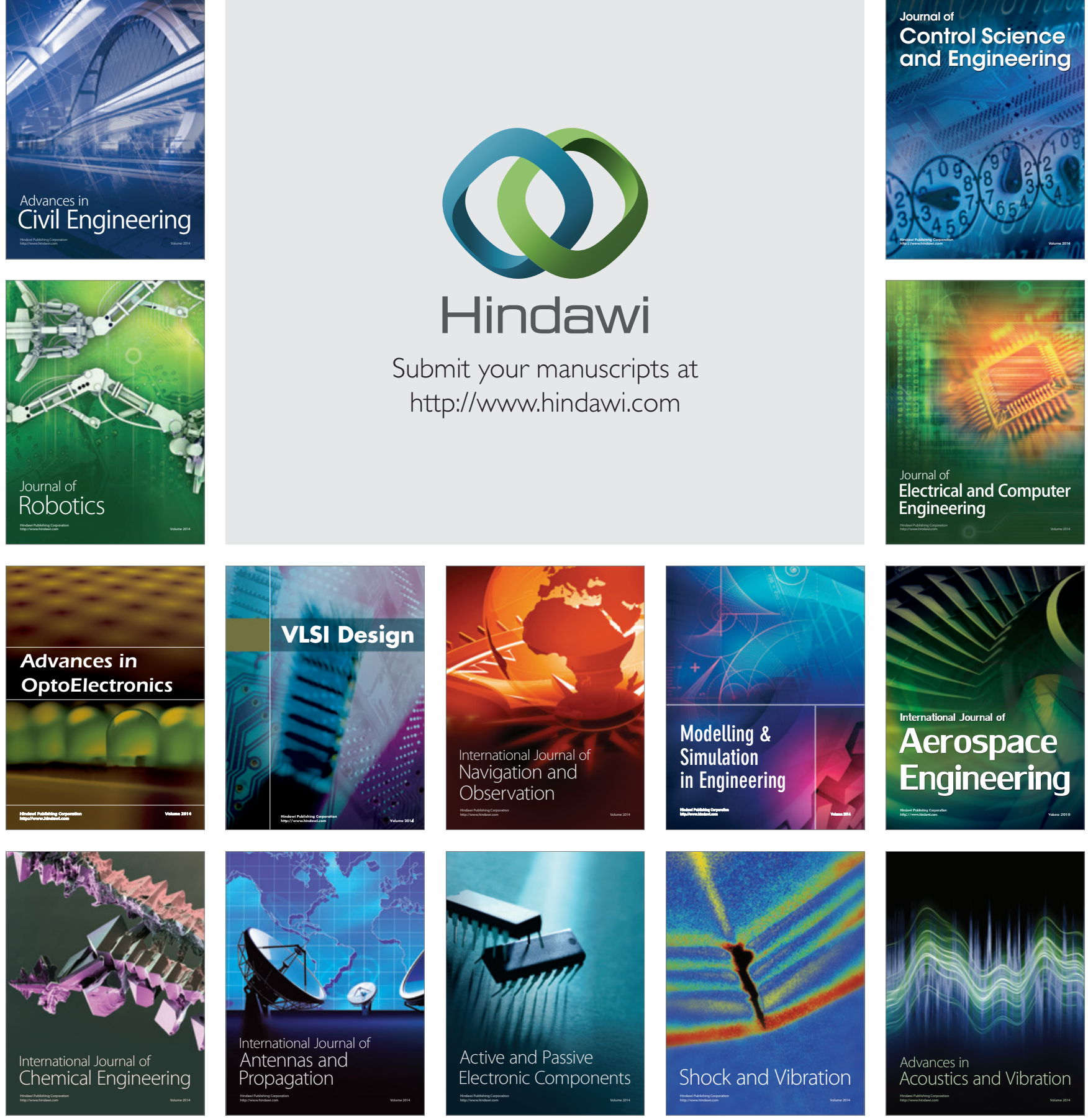